Canadian

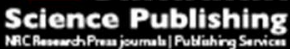

Canadian Geotechnical Journal Revue canadienne de géotechnique

\title{
Geotechnical engineering behaviors of gellan gum biopolymer treated sand
}

\begin{tabular}{|r|l|}
\hline Journal: & Canadian Geotechnical Journal \\
\hline Manuscript ID & cgj-2015-0475.R2 \\
\hline Danuscript Type: & Article \\
\hline Complete List of Authors: & $\begin{array}{l}\text { Chang, Ilhan; Korea Institute of Civil Engineering and Building Technology } \\
\text { (KICT), Geotechnical Engineering Research Institute (GERI) } \\
\text { Im, Jooyoung; Korea Advanced Institute of Science and Technology } \\
\text { Cho, Gye-Chun; Korea Advanced Institute of Science and Technology, } \\
\text { Department of Civil and Environmental Engineering }\end{array}$ \\
\hline Keyword: & $\begin{array}{l}\text { Gellan gum biopolymer, Unconfined compressive strength, Friction angle, } \\
\text { Inter-particle cohesion, Hydraulic conductivity }\end{array}$ \\
\hline & \\
\hline
\end{tabular}

SCHOLARONE $^{\text {Ix }}$

Manuscripts 
Submitted journal: Canadian Geotechnical Journal (Date: June 3, 2016)

\section{Title: Geotechnical engineering behaviors of gellan gum biopolymer treated sand}

List of Authors:

Ilhan Chang

Senior Researcher, SOC Research Institute, Korea Institute of Construction Technology (KICT), Goyang 10223, Republic of Korea

Tel: +82-31-910-0273

Email: ilhanchang@kict.re.kr

Jooyoung Im

Department of Civil and Environmental Engineering,

Korea Advanced Institute of Science and Technology (KAIST), Daejeon 34141,

Republic of Korea

Email: jooyoungim@kaist.ac.kr

Gye-Chun Cho

Corresponding Author, Professor, Department of Civil and Environmental Engineering, Korea Advanced Institute of Science and Technology (KAIST), Daejeon 34141,

Republic of Korea

Tel: $+82-42-869-3622$

Fax: +82-42-869-7200

Email: gyechun@kaist.edu

Number of words: 6,317 (without cover letter, abstract, figures, and tables)

Number of tables: 2

Number of figures: 12

Keywords: Gellan gum biopolymer, Unconfined compressive strength, Friction angle, Interparticle cohesion, Hydraulic conductivity 


\begin{abstract}
Biological approaches have been explored as environmentally friendly alternatives to engineered soil methods in geotechnical engineering practices, recently. The use of microbial induced calcite precipitation, reactive enzymes, and microbial polymers, such as biopolymers, in soil improvement has been studied by researchers around the world. In the present study, gellan gum, a microbial polysaccharide generally used in the food industry due to its hydrogel rheology, was used to strengthen sand. The effects of gellan gum on the geotechnical behaviors of cohesionless sand were evaluated through a series of experimental programs including an unconfined compression test, direct shear test, falling head permeability test, and scanning electron microscopy. The geotechnical properties (friction angle, cohesion, and unconfined compressive strength) of gellan gum-treated sands were determined based on varying moisture conditions: initial, dried, and re-submerged. Gellan gum has a distinct strengthening effect on cohesionless sands through artificial cohesion which varies with the moisture conditions. The strengthening effect of gellan gum on sand appears to be a result of the combination of enhanced bonding between unreactive sand particles and the agglomeration of sand particles through hydrogel condensation, in which the agglomerated sand particles behave as enlarged aggregates in soil.
\end{abstract}

Keywords: Gellan gum biopolymer, Unconfined compressive strength, Friction angle, Inter-particle cohesion, Hydraulic conductivity 


\section{INTRODUCTION}

2

Biological approaches for soil improvement recently have been studied in an effort to address environmental concerns related to improving existing soil materials (e.g., an increased shear strength). A number of studies have investigated the possibility of directly implementing microbial induced calcite precipitation (MICP) using microbes in the soil with the goal of strengthening the soil using a lower carbon footprint than that of ordinary engineering soil practices such as cement mixing (Cheng et al. 2013; DeJong et al. 2006; DeJong et al. 2010; van Paassen et al. 2010; Whiffin et al. 2007). Although MICP is an innovative and environmentally friendly alternative soil treatment method, several drawbacks of this approach have been noted including difficulties in obtaining a uniformly treated soil layer due to the uncertainty of the microbial activity and the secretion quality of the soil, which restricts its application to loose and collapsible sands (Soon et al. 2013). Moreover, microbial ureolysis in the ground releases 2 moles of ammonium ions, $\mathrm{NH}_{4}{ }^{+}$, for every 1 mole of calcite $\mathrm{CaCO}_{3}$ precipitation, which increases the soil $\mathrm{pH}$, forms toxic salts, and emits toxic gas into the atmosphere (Akiyama and Kawasaki 2012; Ferris et al. 2004).

Meanwhile, several attempts to use biological organic matter, such as biopolymers, have been reported to stabilize soil aggregates directly instead of activating microbial responses in the soil, (Chang and Cho 2012, 2014; Chang et al. 2015d; Ferruzzi et al. 2000; Orts et al. 2007; Ringelberg et al. 2014). For example, direct biopolymer mixing of a high-molecular chain structure glucan-type biopolymer, $\beta-1,3 / 1,6$-glucan, results in sufficient workability due to the pseudoplastic rheology of the biopolymer. This enables the formation of a uniform biopolymer-soil mixture providing high strengthening with a low carbon dioxide footprint (Chang and Cho 2012). Specifically, the unconfined compression strength provided by $0.25 \% \beta$-1,3/1,6-glucan mixing $(2.17 \mathrm{MPa})$ is similar to that obtained with $10 \%$ cement mixing (2.65 MPa) showing that biopolymers are capable of achieving similar strengths at significantly lower concentrations (1/10 or lower). Thus, biopolymer soil treatment for geotechnical purposes has the potential to reduce the net amount of mixing materials, particularly materials such as cement that involve a high amount of carbon dioxide emissions during production (8 \% of all global emissions) (Chang et al. 2015b; International Cement Review 2015). 
In addition, recent studies have shown the possibility of using gel-type biopolymers, such as agar gum, xanthan gum, and gellan gum, to enhance the strengthening efficiency in geotechnical soil treatment (Chang et al. 2015a; Chang et al. 2015c; Khatami and O'Kelly 2012). Specifically, thermogelation biopolymers such as agar gum and gellan gum provide significant strengthening. Thermogelating biopolymers initially form a hydrocolloid phase when dissolved in water with a temperature above $90{ }^{\circ} \mathrm{C}$ and then, transform to a hydrogel phase with significantly increased viscosity when cooled to below $40{ }^{\circ} \mathrm{C}$. The firm hydrogel of the thermo-gelation biopolymers forms matrices with mediating particles and enhances the overall strength of the whole network (Huang et al. 2007; McHugh 2003).

The use of gellan and agar biopolymers involves different strengthening mechanisms depending on the soil type. Thermo-gelation biopolymers show stronger adhesion with clayey particles, making it possible to achieve an unconfined compressive strength of $13 \mathrm{MPa}$ for $3 \%$, relative to the soil mass, gellan gum biopolymer mixed kaolin under a dried condition (Chang et al. 2015c).

However, most previous studies have only provided preliminary work introducing biopolymers as a possible new binder material for civil and geotechnical engineering purposes. Although gellan gum forms stronger biopolymer-soil matrices with clayey particles than it does with cohesionless coarse particles, in practical applications, sandy soils are generally preferred over clayey soils due to their superior workability and drainage control. Moreover, sandy soils have a higher strengthening efficiency than that of clayey soil based on the unconfined compressive strength (UCS) of untreated natural soils (Chang et al. 2015a), and many aspects of geotechnical engineering require cohesionless soils with an improved shear strength behavior. For these reasons, sand was used as the target soil for this study.

Using a series of experimental approaches, this study examined in detail the effect of gellan gum biopolymer treatment on cohesionless sand focusing on geotechnical engineering design parameters, specifically, the friction angle, cohesion, and hydraulic conductivity. Furthermore, possible applictions of gellan gum biopolymers for geotechnical engineering purposes are recommended based on the findings of these experimental studies and analyses. 


\section{MATERIALS AND METHODS}

\section{Materials}

Jumunjin sand

\section{Biopolymer: Gellan Gum}

Gellan gum is a high molecular weight polysaccharide that is fermented from Sphingomonas elodea microbes. Low acyl gellan gum biopolymer supplied by Sigma Aldrich (CAS No: 71010-52-1) was used in this study. Low acyl gellan gum partially hydrates in cold water and fully dissolves at temperatures above $90{ }^{\circ} \mathrm{C}$ forming a hydrocolloid phase solution. The viscosity of a gellan gum solution increases with decreasing temperature, and finally, a highly viscous hydrogel is formed below $40^{\circ} \mathrm{C}$ (i.e., thermo-gelation). Thus, hydrogel formation is expected to occur naturally during the mixing process with soil through decreasing temperature.

\section{Sample preparation}

All gellan gum-sand samples were prepared by following the same sample preparation method. First, a gellan solution was prepared by dissolving pure gellan gum into distilled water at $100^{\circ} \mathrm{C}$ according to the target concentration $(0.5,1.0,1.5,2.0$, and $5.0 \%$ relative to the mass of the soil) of the gellan gum-sand mixtures. The initial water content for mixing was set at $30 \%$ of the dry sand weight because it was found that an initial water content of $30 \%$ is is sufficient to fully fill the intergranular voids with biopolymer gels, which leads to a fully saturated condition for gellan gum-sand 
mixtures during sample preparation. Thus, $1.67 \%, 3.33 \%, 5.0 \%$, and $6.67 \%$ gellan gum solutions were prepared to finally deliver $0.5 \%, 1.0 \%, 1.5 \%, 2.0 \%$, and $5.0 \%$ gellan gum-sand mixtures (by weight), respectively.

To prevent immediate cooling and thus ensuring sufficient mixability, dry sand was heated in an oven to $100{ }^{\circ} \mathrm{C}$ before mixing. The heated gellan gum solution and sand were mixed on a laboratory hot plate to minimize temperature reduction during mixing and to form a uniform gellan gum-sand mixture. After mixing, the hot gellan gum-sand mixtures were immediately placed into molds relevant for tests before cooling. Cube samples $(50 \mathrm{~mm} \times 50 \mathrm{~mm} \times 50 \mathrm{~mm})$ were prepared for the unconfined compression tests, while disk samples (diameter $=60 \mathrm{~mm}$, height $=20 \mathrm{~mm}$ ) were molded for use in the direct shear tests.

The strength of biopolymer treated soils strongly depends on the water content of the biopolymersoil mixture (Chang et al. 2015c). Thus, three different moisture conditions were considered in the experimental studies: 1) the initial condition, in which samples were tested immediately after cooling; 2) a dry condition, in which samples were fully dried for 28 days at room temperature $\left(20^{\circ} \mathrm{C}\right)$ with a final water content less than $1 \%$, and 3 ) a re-submerged condition, in which the dried samples were submerged in water for 24 hours before testing. Due to the hydrophilic characteristic of the gellan gum, dried gellan gum gels immediately adsorb water and re-hydrate within 2 hours while higher concentrations require up to 6 hours. Full saturation of all the samples was obtained in less than 6 hours. However, the gellan gum-treated sands were submerged for 24 hours to provide sufficient time for re-hydration and stabilization, in which the gellan gum gels inside the soil recover to the initial concentration before drying. The water content $\left(w / m_{s}\right)$ and biopolymer concentrations (biopolymer to water ratios in mass; $m_{b} / w$ ) of the gellan gum-treated sands at different moisture conditions are summarized in Table 1.

For the re-submerged condition, we think that the adsorbed water interacts with the hydrophilic gellan gum biopolymers rather than with the electrically neutral sand particles. However, this hypothesis is inappropriate for soils that contain clay particles which have hydrophilic double-layer surfaces. 


\section{Unconfined compression tests}

111 Cubic samples $(50 \mathrm{~mm} \times 50 \mathrm{~mm} \times 50 \mathrm{~mm})$ of the gellan gum treated sands were prepared at gellan 112 gum concentrations of $0.5 \%, 1.0 \%$, and $2.0 \%$. Unconfined uniaxial compressive testing was 113 performed with a Universal Testing Machine (UTM). The axial strain rate was controlled at a rate of $1140.5 \mathrm{~mm} / \mathrm{min}(1 \% \mathrm{strain} / \mathrm{min})$. The maximum strength and the stress-strain behaviors were obtained by averaging three different measurements for a single condition.

\section{Direct shear tests}

118 Disk shaped gellan gum-sand samples with a $50 \mathrm{~mm}$ diameter and $20 \mathrm{~mm}$ height were placed into a direct shear apparatus with porous stones placed above and beneath them and confined at 50, 100, 200 , and $400 \mathrm{kPa}$ with a pneumatic actuator for 12 hours before applying horizontal shear. Direct shear tests were performed for the three different moisture conditions mentioned in Section 2.2. The samples for the initial and the re-submerged conditions were tested under a saturated condition by filling the inside of the shear box with water before applying vertical confinement. Horizontal shear with a shear rate of $2 \%$ strain/min was applied under a consolidated-drained condition following the ASTM D 3080 standard (ASTM D3080 / D3080M-11 2011) with confining pressures of 50, 100, 200, and $400 \mathrm{kPa}$. Horizontal shear was applied for 500 seconds to finally induce a $10 \mathrm{~mm}$ horizontal displacement. Horizontal load, vertical strain, and horizontal displacements were obtained automatically through load cell and linear variable differential transformer (LVDT) measurements, for which the electronic measurements were attained with a computerized data acquisition system.

\section{Hydraulic conductivity tests}

132 The initial void ratios of the gellan gum-sand mixtures were within a relatively narrow range between 0.82 and 0.87 , regardless of the gellan gum content in the soil mass. Gellan gum-sand mixtures were prepared and poured into a cylindrical cell with an inner diameter of $70 \mathrm{~mm}$ and a height of $140 \mathrm{~mm}$ (height to diameter ratio $=2: 1$ ) before thermo-gelation. The cylindrical cells were 
136 sealed with parafilm and left to cool for 7 days to prevent loss of moisture from the gellan gum-sand 137 mixtures and thereby preserving the initial mixing conditions.

138 Permeability tests were performed according to the ASTM D 5084 standard (ASTM D5084-10 139 2010) using a flexible wall permeameter at room temperature $\left(20 \pm 1^{\circ} \mathrm{C}\right)$ while the inlet and outlet 140 flows were controlled and maintained using a pressure panel. A head difference of $150 \mathrm{~mm}$ was 141 applied to fully saturate the specimens, and a confining pressure of $30 \mathrm{kPa}$ was applied. When the 142 Skempton B-values (Skempton 1954) of the samples exceeded 95\%, the samples then were considered as fully saturated. After saturation, falling-head permeability tests were performed with a hydraulic gradient of 20 or less. Only the initial condition was considered for the laboratory permeability tests to simulate the bio-clogging effect (Mitchell and Santamarina 2005) induced by instant gellan gum-treatment (e.g., mixing) for saturated (below ground water table) sand deposits in situ.

\section{Scanning Electron Microscopy (SEM)}

SEM images were taken to observe the micro-scale direct interactions between the sand particles and the gellan gum biopolymers. Undisturbed and disturbed $1 \%$ gellan gum-treated sand samples were examined by collecting $0.5 \mathrm{~cm}^{3}$ bulk cubic samples from dried gellan gum-sand mixtures that had not been subjected to any testing, and disturbed samples were prepared by attaching the $1 \%$ gellan gum-sand specimens that had been subjected to failure on an SEM mount (diameter $25 \mathrm{~mm}$ ) using carbon conductive tabs. Carbon paint was applied to the edges and bottoms of both the undisturbed and disturbed sample to provide sufficient grounding. Specimens were coated for 20 seconds using an Osmium Plasma Coater (OPC) with osmium tetroxide $\left(\mathrm{OsO}_{4}\right)$ as the source of osmium. An extreme high-resolution scanning electron microscope was used to observe the surface of the gellan gum-sand samples.

\section{RESULTS AND ANALYSIS}

Unconfined Compressive Strength (UCS) of the gellan gum-treated sand samples 
The values for the unconfined compressive strengths and accompanying water contents of the gellan gum biopolymer treated sands are summarized in Fig. 2 and Table 1. The strength of the gellan gum-sand mixtures increased with increasing biopolymer content regardless of the moisture conditions, while the fully dried condition resulted in the highest values for the unconfined compressive strengths at $130.2,241.9$ and $434.6 \mathrm{kPa}$ for the $0.5 \%, 1 \%$, and $2 \%$ gellan gum, respectively (Fig. 2a). In comparison with the cement treatment, even a small amount of gellan gum treatment increased the dry strength of sand significantly. For instance, the UCS of the $2 \%$ gellan gum-treated sand $(434.6 \mathrm{kPa})$ is higher than that of $12 \%$ cement-treated sand $(380 \mathrm{kPa})$, even though the gellan gum-treated sand has a lower dry density $\left(1,430 \mathrm{~kg} / \mathrm{m}^{3}\right)$ than that of the cement treated sand $\left(1,770 \mathrm{~kg} / \mathrm{m}^{3}\right)$ (Yoon and Abu-Farsakh 2009). Moreover, the UCS of $2 \%$ gellan gum-treated sand is identical to the UCS of densely compacted $\left(1,930 \mathrm{~kg} / \mathrm{m}^{3}\right) 8 \%$ cement-sand mixtures after 7 days of curing (470 kPa) (Cheng et al. 2013).

The UCS behavior of the gellan gum-treated sands is consistent with the varying concentrations of gellan gum gels ( $m_{b} / w$; gellan gum to water ratio, in mass) in the soil (Table 1). Dehydration of the gellan gum gels from the initial to the dried state increases the $m_{b} / w$ significantly, while a higher gellan gum content $\left(m_{b} / m_{s}\right)$ results in the retention of a higher final water content $\left(w / m_{s}\right)$ after drying due to the strong hydration characteristics of the gellan gum biopolymer (Nussinovitch 1997). The increased $m_{b} / w$ with drying is highly correlated to the strengthening efficiency of the gellan gum treatment. Therefore, an increase in strength can be attributed to the densification of the gellan biopolymers, which results in higher $m_{b} / w$ ratios. Previous studies have been conducted on the strength of gels based on the concentration of the biopolymers to the water mass (Banerjee and Bhattacharya 2011). In an earlier study, it was found that the strength of the gels increased with higher $m_{b} / w$ ratios. Because the gellan gum biopolymer has strong hydration capabilities (Nussinovitch 1997) exceeding that of sand particles, the water content of the samples interacts mostly with the gellan gum. Therefore, a change in the water content of the samples can be attributed to a similar change in the $m_{b} / w$ ratios. 
For the re-submerged condition, although the $m_{b} / w$ values were similar to that of the initial state $(\approx 30 \%)$, the UCS values of the re-submerged samples were lower than those of the initial condition samples $(17-23 \%$ lower). Therefore, not only the gellan gum gel concentration but also the hydrorheology (e.g., swelling and disturbance) is an important factor regarding the strength behavior of gellan gum-treated sands. This indicates that even though re-submergence recovers the specimen water content and gellan gum concentration to levels similar to the initial state, subsequent re-wetting after the primary dehydration process does not recover the strength of the gellan gum hydrogels up to the initial condition. However, the strength of the gellan gum-treated sand without any variations in the water content are known to remain stable regardless of the time (Chang et al. 2015c). Thus, it can be concluded that the initial state and strength of gellan gum hydrogels is not recoverable once the gellan gum gel is condensed via dehydration. Further studies are recommended to characterize the strength and micro-rheology variations of the gellan gum-treated sands under subsequent repeated drying and wetting cycles with additional analytical methods such as infrared or EDX (Energy Dispersive X-ray) spectroscopy.

The stress-strain relationships of the gellan gum-treated sands (shown in Fig. 3) provide a better explanation, showing that the dried gellan gum-treated sand had higher stiffness compared to the other conditions (initial and re-submerged). This indicates that inter-particle strengthening results from the formation of thick and high-tensile biopolymer dehydrates (e.g., films) among the sand particles, which has also been observed in previous studies (Chang and Cho 2012; Chang et al. 2015a). However, once the primary dried samples are re-submerged, and the water content is recovered through hydrophilic absorption, the strength of the soil greatly diminishes due to the swelling of the biopolymer hydrogels and the weakening of the biopolymer bonds, while the ductility increases to a level higher than that of the initial conditions. This appears to be the result of partial and sequential swelling of the gellan gum hydrogels beginning at the outermost boundary of the dehydrated gellan gum gels, which initially form thick layers on the sand particles during the primary drying process.

\section{Direct shear strength of the gellan gum-treated sand}




\section{Peak shear behavior}

The peak strengths of the gellan gum-treated sands at different moisture content levels, obtained by direct shear testing, are shown in Fig. 4 . The peak shear strength $\left(\tau_{\text {peak }}\right)$ values of the gellan gum-sand mixtures are increased with the higher biopolymer contents, regardless of the moisture conditions. With the higher biopolymer contents, increased strengthening of the samples is clearly seen for both the initial and dried conditions (Figs. $4 \mathrm{a} \& \mathrm{~b}$ ), while the strengthening effect appears to diminish for the re-submerged samples (Fig. 4c).

Fig 5 shows the peak strength properties (cohesion and friction angle) of the gellan gum-treated sand samples. Once the gellan gum hydrocolloids are mixed with the sand (initial condition), the cohesion of the highly viscous hydrogels increases immediately while the peak friction angle remains almost constant without any noticeable variation identical to the friction angle of $28^{\circ}$ for the untreated wet sand. As the gellan gum gels become denser with drying, both the peak interparticle cohesion $\left(c_{\text {peak }}\right)$ and the peak friction angle $\left(\Phi_{\text {peak }}\right)$ increase significantly with increasing gellan content. Although the $c_{\text {peak }}$ values show a continuous increment up to a $5 \%$ gellan gum content regardless of the moisture condition, the $\Phi_{\text {peak }}$ increment appears to level off and converge after the $2 \%$ gellan gum content. Meanwhile, dehydration of excess gellan gum gels above $2 \%$ does not affect the structural composition of the sand particles. Instead, the particles exhibit enhanced interparticle cohesion due to the higher strength of the highly concentrated gellan gum hydrogels which coat the particle surfaces, enhance the inter-particle contacts and fill the void spaces.

A previous study showed that cement-treated sand, with a $10 \%$ cement to sand ratio by volume or $8 \%$ by mass, remarkably improves the friction angle (as great as $44^{\circ}$ ), while having a negligible effect on the inter-particle cohesion (at a value of $0.42 \mathrm{kPa}$ ) (Krantz 1991). In comparison, the friction angle of an $8 \%$ cement treatment sample is equivalent to that of a sample with a $5 \%$ gellan gum mixture; however, the increase in the cohesion for the cement treatment sample cannot be compared to the remarkable improvement in cohesion for the gellan gum-treated sands (as great as $166.17 \mathrm{kPa}$ for $5 \%$ gellan gum in a dried state). 
The strengthening during gellan gum treatment is due to the condensation and aggregation effects of the high tensile gellan gum hydrogels among the sand particles; on the other hand, the strengthening of the cement treated sand is dominated by the formation and pore filling of newly formulated Calcium-Silicate-Hydrate (C-S-H) crystals inside the particle voids.

Re-submerged specimens experienced a remarkable reduction in $c_{\text {peak }}$ (Fig. 5a) with values even lower than the $c_{\text {peak }}$ of the initial conditions, while $\Phi_{\text {peak }}($ Fig. $5 \mathrm{~b})$ remains higher than that of the initial condition. These results indicate that the re-wetting and swelling of the primary dried gellan gum hydrogels is not reversible. In particular, the decrease in cohesion indicates the possibility that the molecular structures and the bonding of the gellan gum biopolymers have been disturbed.

Overall, $c_{\text {peak }}$ and $\Phi_{\text {peak }}$ increase with higher biopolymer contents; however, at around 2-5\% of the gellan gum biopolymer, the rate of increase in $c_{\text {peak }}$ and $\Phi_{\text {peak }}$ decreases regardless of the moisture conditions. This indicates that there likely is an optimal biopolymer concentration $(\approx 2 \%)$ for the sand treatment when the goal is effective shear strengthening.

\section{Residual shear behavior}

Fig. 6 shows the residual shear strengths of the gellan gum-treated sands under different moisture conditions. The residual strength of the gellan gum-treated sand has a similar behavior regardless of the moisture condition unlike the peak shear strength behavior described above.

The samples for the initial, dry, and re-submerged conditions all show an increase in the residual friction angle $\left(\Phi_{\text {res }}\right)$ and residual cohesion $\left(c_{r e s}\right)$ with higher gellan contents, while the $c_{\text {res }}$ values of the gellan gum-treated sands are almost equal for all of the gellan gum contents regardless of the soil moisture conditions (Fig. 7a). This indicates that the strengthening effect induced by the gellan gum hydrogels in sand persists at high levels of strain which implies persistent inter-particle interlocking and adhesion induced by the hydrogen bonding and high tensile strength of the gellan gum hydrogels (Lee et al. 2004).

However, the $\Phi_{\text {res }}$ values for both the initial and re-submerged gellan gum-sand mixtures are similar at low gellan gum contents, $1.0 \%$ and lower, while the values at the initial state are slightly 
269 higher than those of the re-submerged state for gellan gum contents higher than $2 \%$. Meanwhile, the 270 dried condition sample shows a distinctly higher $\Phi_{\text {res }}$ than that of the moist condition sample (Fig.

7b). Of note, for the gellan gum content below $1 \%$, the $\Phi_{\text {peak }}$ is clearly higher than the $\Phi_{\text {res }}$, while the difference between the $\Phi_{\text {peak }}$ and $\Phi_{\text {res }}$ decreases when the gellan gum content exceeds $1 \%$ (Figs. $5 \mathrm{~b}$ and $7 b)$.

In general, the shear strength of coarse soil increases with greater dry density (Bolton 1986; Terzaghi et al. 1996). Fig. 8a shows the relationship between the peak shear strengths and the dry densities of the gellan gum-treated sand, for which the dry density reflects the actual particle composition. As the dry density increases, the peak shear strength generally increases, regardless of the biopolymer content and wet conditions.

Meanwhile, with an increase in the biopolymer content relative to the mass of soil, the shear strength increment decreases, shown in Fig. $8 \mathrm{~b}$, due to a unit dry density $\left(1 \mathrm{~g} / \mathrm{cm}^{3}\right)$ increment (i.e., the ratio between the change in shear strength for a subjective change in dry density; $\Delta \tau_{D S} / \Delta \gamma_{d}\left[\mathrm{MPa} \cdot \mathrm{cm}^{3}\right.$ /g]). This indicates that the soil composition has less of an effect on the strengthening mechanism of the gellan gum-treated sands at higher gellan gum contents, and instead, the majority of the strengthening results from the interparticle bonding provided by the gellan gum hydrogels. The $\Delta \tau_{D S} /$ $\Delta \gamma_{d}$ ratio shows a dramatic degradation with increased gellan gum content and finally levels off at the $2-5 \%$ gellan gum content. However, the peak interparticle cohesion $\left(c_{\text {peak }}\right)$ increases inversely to the $\Delta \tau_{D S} / \Delta \gamma_{d}$ trend. Thus, the strengthening mechanism of the gellan gum-treated sands appears to be less dependent on the structural composition of the sand particles, whereas it is strongly affected by the rheology and strength of the gellan gum hydrogels existing inside.

\section{Shearing mechanism of the gellan-treated sand samples}

The condensation and aggregation mechanism of gellan gum-treated sands is schematically shown in Fig. 9. Natural (untreated) sand has no chemical inter-particle bonding between sand particles, only along the shear band (Fig. 9a), resulting in individual particle movement, rotation and overturning (Fig. 9b). Meanwhile, gellan gum hydrogels provide artificial inter-particle cohesion which 
strengthens with condensation and finally binds particles into agglomerates through increased particle connections and inter-particle bridging. This causes several soil particles to act as a larger single aggregate which requires a larger dilation angle and rotational frustration as well as an increased peak friction angle shown in Figs. 4, 5b and 9c. As such, gellan treated sands have high interparticle cohesion and friction angle values, especially in the dried state compared to those of untreated sand.

The values for the residual friction angle $\left(\Phi_{\text {res }}\right)$ of the dried gellan gum-treated sands are higher than those of both moist (i.e., initial and re-submerged states) gellan gum-sand mixtures in all cases (Fig. 7b). This can be attributed to the microscopic structure of the crushed gellan gum-sand mixtures; this microstructure is identical to that of the residual condition sample that was subjected to shearing. Dried and condensed gellan gum gels break into fragments under large strains; these fragments are expected to behave as frictional materials, improving interlocking between sand particles even in the residual state. Although their viscosities are lower than those of the dried gels, the initial and resubmerged gellan gum hydrogels also have higher $\Phi_{\text {res }}$ values than those of the untreated sand. Moist hydrogels are expected to be partially crushed due to the motions of the sand particles; this can also possibly enhance the friction characteristics of the sand particles at large strain shearing through interface attractive adhesive forces between the sand surfaces and the viscous gels (Gong et al. 1999; Tominaga et al. 2008). Thus, it becomes clear that the existence of gellan gum hydrogels inside soil increases both the peak and residual friction properties through hydrogel condensation.

\section{Scanning Electron Microscopy (SEM)}

SEM images of the 1\% gellan gum-sand mixtures are shown in Fig. 10. Undisturbed gellan gumtreated sand (Fig. 10a) shows that the gellan gum biopolymers coagulate into gellan gum films which form connection bridges between adjacent particles (Fig. 10b). This results in an increase of both the peak strength and the elastic modulus (Fig. 3) which was also observed in previous biopolymer studies, including research on beta-glucan (Chang and Cho 2012) and xanthan gum (Chang et al. 2016; Chang et al. 2015a). Therefore, the gellan gum-sand matrix formation and hardening 
mechanism through dehydration is expected to be governed by the densification $\left(m_{b} / w\right.$ increase; Table 1) of the gellan gum hydrogels inside the sand pores.

\section{Effect of water on the behavior of the gellan gum-treated sands}

One drawback to the strengthening mechanism of gellan gum-treated sand is the decrease in strength when the primary dried gellan gum-sand mixtures are re-submerged in water. With dehydration, the condensed gellan gum hydrogels force sand particles to interact more directly and tightly because the gellan biopolymers form increased particle interactions (Fig. 10a) and fibrous clumps (Fig. 10c) which enhance the strength of the gellan gum-treated sand samples. When the dried gellan gum-treated sands are subjected to water again, the hydrophilic gellan gum-water interaction and accompanying swelling (Fig. 2b) appear to degrade the strength properties such as the strength and stiffness (Fig. 3) as well as the inter-particle cohesion (Fig. 5a) of the gellan gum gels inside soil, regardless of the gellan gum to sand ratio. This is consistent with the phenomenon of an unrecoverable initial state of gellan gum hydrogels once they are condensed through dehydration outlined in section 3.1. Thus, it can be concluded that the initial state and strength of the gellan gum hydrogels is not recoverable once the gellan gum gel is condensed through dehydration.

The hypothesis that gellan gum-treated sand with varying water contents has different geotechnical engineering behaviors is shown in Fig. 11. In the initial state, the gellan gum hydrocolloids uniformly disperse between sand particles, and the viscosity increases by thermo-gelation (cooling) (Fig. 11a). As the gellan gum hydrogels undergo dehydration, the thickened gels begin to coagulate around the sand particles, while the decrease in volumetric moisture content leads to the formation of discrete air voids along the gellan gum gels (Fig. 11b). Once the gellan gum gels are dried, condensed film-like gellan gum gels enhance the inter-particle interaction (Figs. 3 and 5a) through biopolymer matrix formation (Figs. 10a \& b) among the sand particles (Fig. 11c). However, once the dried gellan gumtreated sand is re-submerged, the dried gels are expected to absorb water due to their hydrophilicity. Gradual swelling of the gellan gum gels from the outside rim results in weaker viscosity (or stiffness) of the re-hydrated gellan gum gel relative to that of the initial / uniform hydrocolloid state (Fig. 11a). 
349 The strength difference of the gellan gum gels between the initial and re-submerged conditions (Figs.

3502 and 5) implies that a uniform initial gel matrix cannot be recovered by the re-wetting and

\section{Hydraulic conductivity of the gellan gum-treated sand samples}

The hydraulic conductivity of the gellan gum-treated sand in the initial state decreases exponentially, from an untreated condition $\left(\sim 2.1 \times 10^{-4} \mathrm{~cm} / \mathrm{s}\right)$ to $1 \%$ gellan gum content $\left(\sim 2.6 \times 10^{-8}\right.$ $\mathrm{cm} / \mathrm{s}$ ) shown in Fig. 12. Then, for higher gellan gum contents, the hydraulic conductivity converges to a very low value $\left(\sim 8.2 \times 10^{-9} \mathrm{~cm} / \mathrm{s}\right)$ which correlates with an impermeable layer.

The convergence of gellan gum-treated sands above a $1 \%$ gellan gum content toward a stabilized hydraulic conductivity behavior appears to be induced by a combination of the water holding capacity and the pore-filling characteristic of the gellan gum hydrogels under a saturated condition. Within a fixed pore size, the water content of a fully saturated specimen remains constant; as such, an increase in the gellan gum content will decrease the permeability by reducing the number of easily moveable water molecules inside the specimen. Moreover, thick gellan gum hydrogels are expected to fill the pore spaces of the sands by creating multiple film-type gellan gum layers on the sand particle surfaces, consequently reducing the pore spaces (bio-clogging). Thus, it can be concluded that gellan gum shows promise in terms of controlling the hydraulic conductivity, a feature that can be applied to various environmentally friendly water control purposes in geotechnical engineering.

The bio-clogging efficiency increased with greater gellan gum content; once the gellan gum hydrogel reached a concentration for which the water molecules inside the pores completely interacted with the biopolymer molecules, the hydraulic conductivity stabilized to a lower bound. From this point, the excess amount of gellan gum no longer had a large effect on decreasing the hydraulic conductivity. However, for higher hydraulic pressure gradient conditions ( $\mathrm{i}>20$ ), it is expected that a greater amount of gellan gum will be required to produce a similar hydraulic conductivity control effect. It is hence recommended that further studies be performed to investigate the hydraulic conductivity behavior of gellan gum treated soils under large hydraulic pressure 
conditions and to evaluate the potential of gellan gum biopolymer use in deep grouting or mixing purposes.

\section{DISCUSSION}

\section{Economic feasibility of gellan gum use for geotechnical engineering purposes}

Currently, the economic feasibility of using gellan gum to replace ordinary cement in geotechnical engineering applications appears to be rather low. Specifically, the current material price of gellan gum is roughly $20,000 \mathrm{USD} / \mathrm{ton}^{1}$, while the price of ordinary cement is only $100 \mathrm{USD} / \mathrm{ton}^{2}$ (Kelly and Matos 2014; Morris et al. 2012).

Taking into account that lower concentrations of gellan gum are required compared with cement, for instance, $1 \%$ gellan gum treatment has an equivalent strength to a $10 \%$ cement treatment, and the material price to treat 1 ton of soil amounts to approximately 200 USD for gellan gum and 10 USD for cement. This large difference in price makes the current use of gellan gum in soil treatment impractical. However, the current market price is for food grade gellan gum, and the market for lower grade gellan gum has not yet been developed.

If the market for gellan gum were to develop further, allowing for greater commercialization of gellan gum, the prices could decrease significantly. This is what transpired with the commercialization of xanthan gum, with the price dropping from 30,000 USD/ton to 3,000 USD/ton within 20 years (Imeson 2010). With proper marketing and commercialization, it can be assumed that the price of gellan gum could reach the current price of xanthan gum (3 USD/kg). Additionally, high purity food grade gellan gum is unnecessary for construction purposes, and with a lower required purity, production costs could be greatly reduced. Without the cost of additional purification, the total cost could be significantly lower than the anticipated cost of $3 \mathrm{USD} / \mathrm{kg}$, reaching $1.5-2 \mathrm{USD} / \mathrm{kg}$. At this point, the cost of treating 1 ton of soil with $1 \%$ gellan gum would be approximately $15-20$ USD, which would be comparable with that of cement (10 USD).

\footnotetext{
${ }^{1}$ Material trade price of bulk (1 ton) low acyl gellan gum (www.alibaba.com)

${ }^{2}$ Market price of cement in the United States in 2014.
} 
For future implementation, a heated gellan gum solution (over $90{ }^{\circ} \mathrm{C}$ ) can be injected (e.g., grouting) or mixed (e.g., deep auger mixing) directly with in-situ soil, to facilitate quick setting by thermo-gelation due to a temperature decrease during implementation. With the cost for heating the gellan solution for soil treatment, a rough calculation of the required energy was performed assuming an overall $50 \%$ efficiency with gas heating equipment (Nakićenović et al. 1998). In detail, approximately $588 \mathrm{MJ}$ is required to treat 1 ton of soil with $300 \mathrm{~kg}$ of heated $3.3 \%$ gellan gum solution. Generally, gasoline has an energy density of $46.4 \mathrm{MJ} / \mathrm{kg}$ (Nakićenović et al. 1998), and thus, the average fuel cost to treat 1 ton of soil with thermo-gelated gellan gum treatment becomes approximately 9.63 USD/ton, considering the average market price of gasoline in the U.S. in 2014 (Kilian 2014). This value is only the cost for the required energy and is highly susceptible to change depending on many variables such as heating mechanisms and methods.

\section{Possible applications of the gellan gum treatment in geotechnical engineering practices}

Gellan gum is a biodegradable biopolymer with a high sensitivity to the presence of water. Therefore, any permanent application using gellan gum-treated soils may be difficult. However, because the material is non-toxic and ecofriendly, its use in temporary construction may be extremely beneficial. As the results of the current study show, the use of gellan gum in sand provides a cohesive strength not found in such sands.

The increased inter-particle cohesion and the friction angles of the gellan gum-treated sand are expected to provide significant ground improvement in practical geotechnical applications, regardless of exposure to water. To address considerations for foundation engineering, the ultimate bearing capacities $\left(q_{\text {ult(square })}\right)$ at a $1 \mathrm{~m}$ depth of gellan gum-treated sand deposits for square-type $(1 \mathrm{~m} \times 1 \mathrm{~m})$ foundations are presented in Table 1. Table 1 is shown in accordance with Terzaghi's formulas on ultimate bearing capacities (Das and Sobhan 2014). Table 1 shows a significant increase in the $q_{\text {ult(square) }}$ values with higher gellan gum content. Although both the interparticle cohesion and the friction angle values of gellan gum-treated sand vary with different moisture conditions, the strengthening effects for all moisture conditions improve the $q_{\text {ult(square) }}$ of the sands remarkably. For 
instance, even at the weakest gellan gum treatment condition ( $0.5 \%), q_{\text {ult(square) }}$ increased by $266 \%$ from that of the untreated sand, $269 \mathrm{kPa}$, reaching a final value of $983 \mathrm{kPa}$. The highest $q_{\text {ult(square) }}$ was obtained from $5 \%$ gellan gum treated sand in a dry condition, reaching an extremely high value of 44 MPa. Thus, it can be cautiously concluded that the strengthening efficiency of the gellan gum treatment on sandy soils provides effective and sufficient ground improvement for various geotechnical engineering applications including foundation design.

In terms of temporary construction purposes, the proposed treatment may be valuable in applications such as erosion resistance at construction sites, by reducing the amount of airborne dust particles produced by the construction process and the problems that arise with such aeolian dust particles (Pye 1987). It can also provide temporary strengthening of unpaved ground at construction sites, including that used for temporary roads, allowing easier movement and use of heavy machinery.

This technology also shows promise as a practical solution for quick permeability control. Unlike cement, because gellan gum does not require a long period of time to set, a quick injection of a gellan gum solution may allow for rapid application of a permeability control, and such quick applications can be helpful in reducing time and material costs (Nimah et al. 1983).

The major benefit of biopolymer soil treatment technology is that after the service period of a given temporary support or ground improvement, the biodegradability of biopolymers will allow for natural decomposition while simultaneously providing a carbon food source for local vegetation without any demolition waste.

\section{CONCLUSIONS}

As an environmentally friendly biopolymer used for soil improvement, the gellan treated sands showed relatively high strengthening even at low concentrations. The unconfined compression test results for the gellan sands $(434 \mathrm{kPa})$ were comparable to those of $12 \%$ cement treated sands $(380$ $\mathrm{kPa}$ ). In terms of shear strength, the gellan sands showed large improvements in the cohesion and the friction angle of the sands. With large improvements in the cohesion and the friction angle at low concentrations, gellan gum can be easily implemented to improve the strength and quality of shallow 
soils.

Additionally, due to the pore filling effects of the gellan hydrogels, the use of gellan has been shown to be capable of decreasing the permeability of sands to $1 \times 10^{-8} \mathrm{~cm} / \mathrm{s}$. The decrease in permeability when applying gellan gum into the soil is almost immediate; therefore, when used as a permeability-controlling barrier, gellan gum can provide a fast alternative to sufficiently reduce the permeability of soils.

Although gellan gum is highly sensitive to water, the retention of the strength and friction angle even in the re-submerged state indicates a certain degree of durability with drying and wetting cycles. With sufficient durability, the working life of biopolymers will be adequate for numerous construction purposes. In addition, because gellan gum is biodegradable and eco-friendly, its use will allow for natural disposal of the biopolymer into the ecosystem without causing any harm to the environment. Therefore, this method of soil improvement offers many benefits compared to current methods, especially in applications involving temporary improvement. The use of cement may allow for strong and durable engineered ground construction, but due to its overly high durability and difficulties in disposal, its use in temporary applications is highly undesirable. The present results show that gellan gum has various benefits for ground improvement including improvements in strength, friction angle, and reduction of permeability.

\section{ACKNOWLEDGEMENTS}

The research described in this paper was financially supported by a National Research Foundation of Korea (NRF) grant funded by the Korean government (MSIP) (No. 2015R1A2A2A03006268), by a grant from the Strategic Research Project (Development of Key Excavation Solutions for Expandable Urban Underground Space) funded by the Korea Institute of Civil Engineering and Building Technology (KICT), and by the KAIST End-Run Program (No. N01150661) supported by the Korea Ministry of Science, ICT and Future Planning (MISP). The $2^{\text {nd }}$ author is supported by the "U-City Master and Doctor Course Grant (Education) Program" under the Korea Ministry of Land, Infrastructure and Transport (MOLIT). 


\section{REFERENCES}

484

485

486

487

488

Akiyama, M., and Kawasaki, S. 2012. Microbially mediated sand solidification using calcium phosphate compounds. Engineering Geology 137-138(0): 29-39. doi: http://dx.doi.org/10.1016/j.enggeo.2012.03.016.

ASTM D3080 / D3080M-11. 2011. Standard test method for direct shear test of soils under consolidated drained conditions. ASTM International, West Conshohocken, PA.

ASTM D5084-10. 2010. Standard test methods for measurement of hydraulic conductivity of saturated porous materials using a flexible wall permeameter. ASTM International West Conshohocken, PA.

Banerjee, S., and Bhattacharya, S. 2011. Compressive textural attributes, opacity and syneresis of gels prepared from gellan, agar and their mixtures. Journal of Food Engineering 102(3): 287-292. doi: http://dx.doi.org/10.1016/j.jfoodeng.2010.08.025.

Bolton, M.D. 1986. The strength and dilatancy of sands. Géotechnique 36(1): 65-78. doi: doi:10.1680/geot.1986.36.1.65.

Chang, I., and Cho, G.-C. 2012. Strengthening of Korean residual soil with $\beta-1,3 / 1,6$-glucan biopolymer. Construction and Building Materials 30(0): 30-35. doi: http://dx.doi.org/10.1016/j.conbuildmat.2011.11.030.

Chang, I., and Cho, G.-C. 2014. Geotechnical behavior of a beta-1,3/1,6-glucan biopolymer-treated residual soil. Geomechanics and Engineering 7(6): 633-647. doi: 10.12989/gae.2014.7.6.633.

Chang, I., Im, J., and Cho, G.-C. 2016. Introduction of microbial biopolymers in soil treatment for future environmentally-friendly and sustainable geotechnical engineering. Sustainability 8(3): 251. doi: $10.3390 /$ su8030251.

Chang, I., Im, J., Prasidhi, A.K., and Cho, G.-C. 2015a. Effects of Xanthan gum biopolymer on soil strengthening. Construction and Building Materials 74(0): 65-72. doi: http://dx.doi.org/10.1016/j.conbuildmat.2014.10.026.

Chang, I., Jeon, M., and Cho, G.-C. 2015b. Application of microbial biopolymers as an alternative construction binder for earth buildings in underdeveloped countries. International Journal of Polymer Science 2015: 9. doi: $10.1155 / 2015 / 326745$.

Chang, I., Prasidhi, A.K., Im, J., and Cho, G.-C. 2015c. Soil strengthening using thermo-gelation biopolymers. Construction and Building Materials 77(0): 430-438. doi: http://dx.doi.org/10.1016/j.conbuildmat.2014.12.116.

Chang, I., Prasidhi, A.K., Im, J., Shin, H.-D., and Cho, G.-C. 2015d. Soil treatment using microbial biopolymers for anti-desertification purposes. Geoderma 253-254(0): 39-47. doi: http://dx.doi.org/10.1016/j.geoderma.2015.04.006.

Cheng, L., Cord-Ruwisch, R., and Shahin, M.A. 2013. Cementation of sand soil by microbially induced calcite precipitation at various degrees of saturation. Canadian Geotechnical Journal 50(1): 81-90. doi: 10.1139/cgj2012-0023.

Das, B.M., and Sobhan, K. 2014. Principles of geotechnical engineering. Eighth edition, SI / ed. Cengage Learning, Australia.

DeJong, J.T., Fritzges, M.B., and Nusslein, K. 2006. Microbially induced cementation to control sand response to undrained shear. Journal of Geotechnical and Geoenvironmental Engineering 132(11): 1381-1392. doi: doi:10.1061/(ASCE)1090-0241(2006)132:11(1381).

DeJong, J.T., Mortensen, B.M., Martinez, B.C., and Nelson, D.C. 2010. Bio-mediated soil improvement. Ecological Engineering 36(2): 197-210. doi: http://dx.doi.org/10.1016/j.ecoleng.2008.12.029. 
Ferris, F.G., Phoenix, V., Fujita, Y., and Smith, R.W. 2004. Kinetics of calcite precipitation induced by ureolytic bacteria at 10 to $20^{\circ} \mathrm{C}$ in artificial groundwater. Geochimica et Cosmochimica Acta 68(8): 1701-1710. doi: http://dx.doi.org/10.1016/S0016-7037(03)00503-9.

Ferruzzi, G.G., Pan, N., and Casey, W.H. 2000. Mechanical properties of gellan and polyacrylamide gels with implications for soil stabilization. Soil Science 165(10): 778-792. doi: 10.1097/00010694-200010000-00003.

Gong, J., Iwasaki, Y., Osada, Y., Kurihara, K., and Hamai, Y. 1999. Friction of gels. 3. friction on solid surfaces. The Journal of Physical Chemistry B 103(29): 6001-6006. doi: 10.1021/jp9902553.

Huang, M., Kennedy, J.F., Li, B., Xu, X., and Xie, B.J. 2007. Characters of rice starch gel modified by gellan, carrageenan, and glucomannan: A texture profile analysis study. Carbohydrate Polymers 69(3): 411-418. doi: http://dx.doi.org/10.1016/j.carbpol.2006.12.025.

Imeson, A. 2010. Food stabilisers, thickeners and gelling agents. Wiley-Blackwell Pub., Chichester, U.K. ; Ames, Iowa.

International Cement Review. 2015. Global cement report 11th Edition. International Cement Review.

Kelly, T.D., and Matos, G.R. 2014. Historical statistics for mineral and material commodities in the United States (2016 version). U.S. Geological Survey.

Khatami, H., and O'Kelly, B. 2012. Improving mechanical properties of sand using biopolymers. Journal of Geotechnical and Geoenvironmental Engineering 139(8): 1402-1406. doi: 10.1061/(ASCE)GT.19435606.0000861 .

Kilian, L. 2014. The impact of the shale oil revolution on U.S. oil and gasoline prices.

Krantz, R.W. 1991. Experimental and Numerical Modelling of Continental Deformation Measurements of friction coefficients and cohesion for faulting and fault reactivation in laboratory models using sand and sand mixtures. Tectonophysics 188(1): 203-207. doi: http://dx.doi.org/10.1016/0040-1951(91)90323-K.

Lee, K.Y., Shim, J., and Lee, H.G. 2004. Mechanical properties of gellan and gelatin composite films. Carbohydrate Polymers 56(2): 251-254. doi: http://dx.doi.org/10.1016/j.carbpol.2003.04.001.

McHugh, D.J. 2003. A guide to the seaweed industry. Food and Agriculture Organization of The United Nations, Rome, Italy.

Min, T.-K., and Huy, P.T. 2010. A Soil-Water hysteresis model for unsaturated sands based on fuzzy set plasticity theory. KSCE Journal of Civil Engineering 14(2): 165-172. doi: 10.1007/s12205-010-0165-x.

Mitchell, J., and Santamarina, J. 2005. Biological Considerations in Geotechnical Engineering. Journal of Geotechnical and Geoenvironmental Engineering 131(10): 1222-1233. doi: 10.1061/(ASCE)10900241(2005)131:10(1222).

Morris, E.R., Nishinari, K., and Rinaudo, M. 2012. Gelation of gellan - A review. Food Hydrocolloids 28(2): 373-411. doi: http://dx.doi.org/10.1016/j.foodhyd.2012.01.004.

Nakićenović, N.A., Grübler, A., and McDonald, A. 1998. Global energy : perspectives. Cambridge University Press, New York.

Nimah, M.N., Ryan, J., and Chaudhry, M.A. 1983. Effect of synthetic conditioners on soil water retention, hydraulic conductivity, porosity, and aggregation. Soil Science Society of America Journal 47(4): 742-745. doi: 10.2136/sssaj1983.03615995004700040026x.

Nussinovitch, A. 1997. Hydrocolloid applications : gum technology in the food and other industries. Chapman \& Hall, London. 
563 Orts, W., Roa-Espinosa, A., Sojka, R., Glenn, G., Imam, S., Erlacher, K., and Pedersen, J. 2007. Use of 564 Synthetic Polymers and Biopolymers for Soil Stabilization in Agricultural, Construction, and Military 565 Applications. Journal of Materials in Civil Engineering 19(1): 58-66. doi: 10.1061/(ASCE)0899566 1561(2007)19:1(58).

567 Park, L.K., Suneel, M., and Chul, I.J. 2008. Shear strength of jumunjin sand according to relative density. 568 Marine Georesources \& Geotechnology 26(2): 101-110. doi: 10.1080/10641190802022445.

569 Pye, K. 1987. Aeolian dust and dust deposits. Academic Press, London ; Orlando.

570 Ringelberg, D.B., Cole, D.M., Foley, K.L., Ruidaz-Santiago, C.M., and Reynolds, C.M. 2014. Compressive 571 strength of soils amended with a bacterial succinoglycan: effects of soluble salts and organic matter. Canadian Geotechnical Journal 51(7): 747-757. doi: 10.1139/cgj-2012-0369.

Skempton, A.W. 1954. The Pore-Pressure Coefficients A and B. Géotechnique 4(4): 143-147. doi: doi:10.1680/geot.1954.4.4.143.

Soon, N., Lee, L., Khun, T., and Ling, H. 2013. Improvements in engineering properties of soils through microbial-induced calcite precipitation. KSCE Journal of Civil Engineering 17(4): 718-728. doi: 10.1007/s12205-013-0149-8.

Terzaghi, K., Peck, R.B., and Mesri, G. 1996. Soil mechanics in engineering practice. 3rd ed. John Wiley \& 579 Sons, New York.

580 Tominaga, T., Kurokawa, T., Furukawa, H., Osada, Y., and Gong, J.P. 2008. Friction of a soft hydrogel on rough solid substrates. Soft Matter 4(8): 1645-1652. doi: 10.1039/B802568A.

582

van Paassen, L., Ghose, R., van der Linden, T., van der Star, W., and van Loosdrecht, M. 2010. Quantifying Biomediated Ground Improvement by Ureolysis: Large-Scale Biogrout Experiment. Journal of Geotechnical and Geoenvironmental Engineering 136(12): 1721-1728. doi: 10.1061/(ASCE)GT.1943-5606.0000382. improvement technique. Geomicrobiology Journal 24(5): 417-423. doi: 10.1080/01490450701436505. 


\section{List of Figures}

Figure 1. Particle size distribution of Jumunjin sand.

Figure 2. Unconfined compressive strength (a) and water content (b) of gellan gum-treated sand.

Figure 3. Stress-strain relationships of gellan gum-treated sand under unconfined compression.

Figure 4. Peak strength of gellan gum-treated sand. (a) Initial condition. (b) Dried condition (28 days). (c) Re-submerged condition (24 hours before testing).

Figure 5. Peak strength properties of gellan gum-treated sand. (a) Cohesion. (b) Friction angle.

Figure 6. Residual strength of gellan gum-treated sand. (a) Initial condition. (b) Dried condition (28 days). (c) Re-submerged condition (24 hours before testing).

Figure 7. Residual strength properties of gellan gum-treated sand. (a) Cohesion. (b) Friction angle.

Figure 8. Peak shear strength of gellan gum-treated sand (a) versus dry density (b) versus gellan gum content.

Figure 9. Schematic diagram of sands under shearing. (a) Natural (untreated) sand before shear. (b) Untreated sand under shear in which particles rotate along the shear plane. (c) Aggregation effect of gellan gum-sand mixtures, which induces a higher friction angle $\left(\phi_{\text {peak }}\right)$ in a dried condition.

Figure 10. SEM images of $1 \%$ gellan gum-treated sand. (a) Before UTM testing (undisturbed). (b) Gellan gum films accumulated between particles (undisturbed). (c) After UTM testing (crushed)

Figure 11. Drying and wetting mechanisms of gellan treated sands (a) Initial condition. (b) Propagation of cracks in gel with drying. (c) Dried condition. (d) Re-submerged condition.

Figure 12. Hydraulic conductivity of gellan gum-treated sand in the initial state (without drying) with biopolymer content (by weight). 
Table 1. Water content $\left(w / m_{s}\right)$ and biopolymer concentration (biopolymer to water ratios in mass; $m_{b}$ $/ w$ ) of gellan gum-treated sands at initial, after drying, and after re-submergence.

\begin{tabular}{c|c|c|c|c|c|c}
\hline \multirow{2}{*}{$\begin{array}{c}\text { Gellan gum content, } \\
m_{b} / m_{s}[\%]\end{array}$} & \multicolumn{2}{|c|}{ Initial } & \multicolumn{2}{c}{ Dry } & \multicolumn{2}{c}{ Re-submerged } \\
\cline { 2 - 7 } & $w / m_{s}$ & $m_{b} / w$ & $w / m_{s}$ & $m_{b} / w$ & $w / m_{s}$ & $m_{b} / w^{*}$ \\
\hline 0.5 & 30.0 & 1.67 & 0.5 & 100 & 26.0 & 1.92 \\
1.0 & 30.0 & 3.33 & 0.7 & 143 & 28.0 & 3.57 \\
1.5 & 30.0 & 5.00 & 0.8 & 187 & 28.3 & 5.30 \\
2.0 & 30.0 & 6.67 & 0.9 & 222 & 29.5 & 6.78 \\
\hline
\end{tabular}

*Maximum possible biopolymer to water ratios for the re-submerged condition 
Table 2. Bearing capacities of gellan treated soils

\begin{tabular}{|c|c|c|c|c|c|c|}
\hline \multicolumn{2}{|c|}{ Gellan gum content [\%] } & 0 (untreated) & 0.5 & 1 & 2 & 5 \\
\hline \multirow{3}{*}{$c[\mathrm{kPa}]$} & Initial & 0.0 & 24.7 & 33.2 & 85.6 & 103.5 \\
\hline & Dry & 0.0 & 32.6 & 67.8 & 114.3 & 166.2 \\
\hline & Submerged & 0.0 & 18.0 & 23.3 & 40.6 & 44.7 \\
\hline \multirow{3}{*}{$\phi\left[^{\circ}\right]$} & Initial & 27.9 & 28.3 & 29.77 & 29.7 & 29.5 \\
\hline & Dry & 27.9 & 34.6 & 36.85 & 42.7 & 47.3 \\
\hline & Submerged & 27.9 & 29.3 & 30.35 & 33.4 & 36.0 \\
\hline \multirow{3}{*}{$\mathrm{q}_{\text {ult(square) }}[\mathrm{kPa}]$} & Initial & 269 & 1,127 & 1,618 & 3,612 & 4,243 \\
\hline & Dry & 269 & 2,536 & 5,726 & 17,340 & 44,166 \\
\hline & Submerged & 269 & 983 & 1,304 & 2,611 & 3,713 \\
\hline \multirow{3}{*}{$\begin{array}{l}\text { Improvement } \\
\text { efficiency [\%] }\end{array}$} & Initial & - & 319 & 502 & 1,245 & 1,480 \\
\hline & Dry & - & 844 & 2,032 & 6,356 & 16,343 \\
\hline & Submerged & - & 266 & 385 & 872 & 1,282 \\
\hline
\end{tabular}




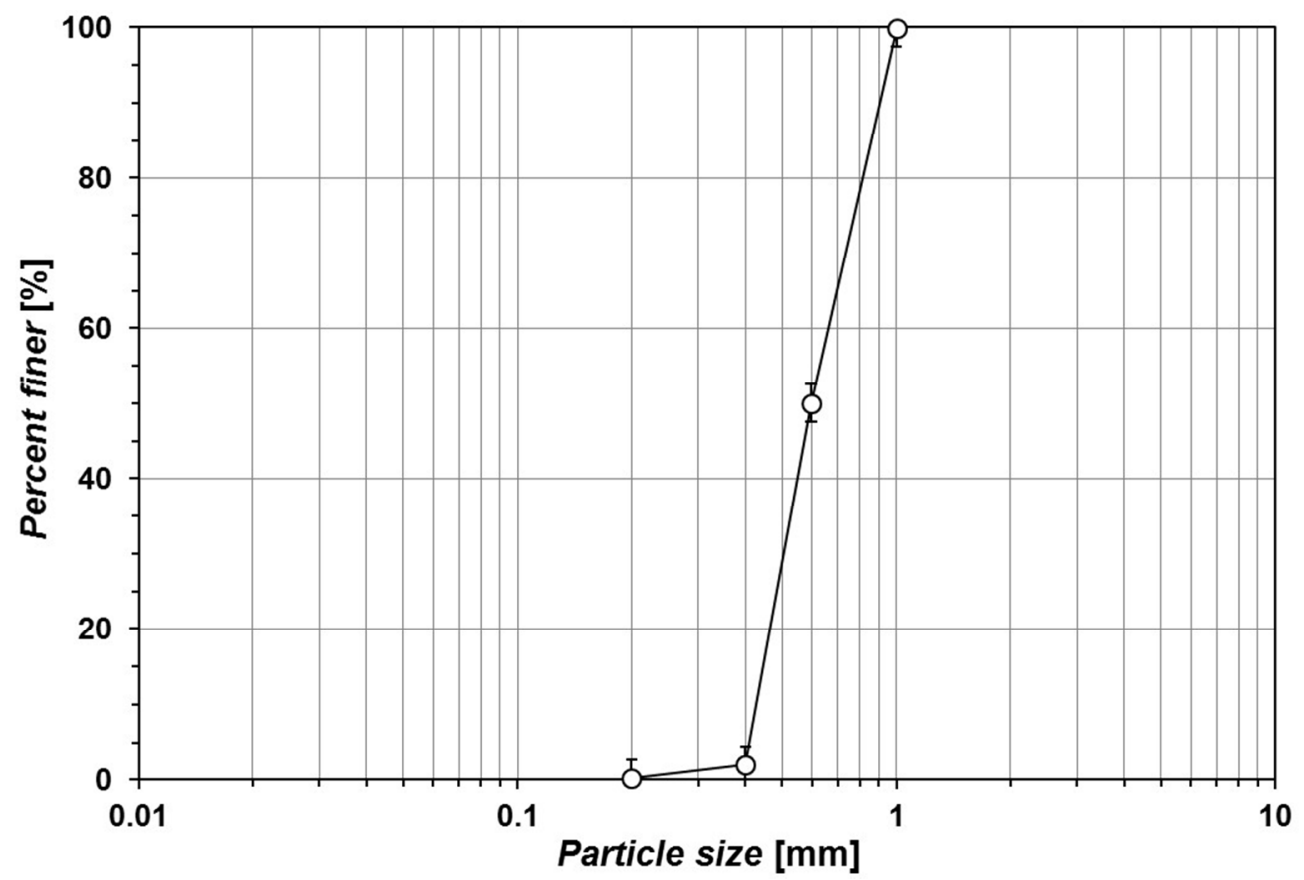

Figure 1. Particle size distribution of Jumunjin sand. $180 \times 120 \mathrm{~mm}(150 \times 150 \mathrm{DPI})$ 

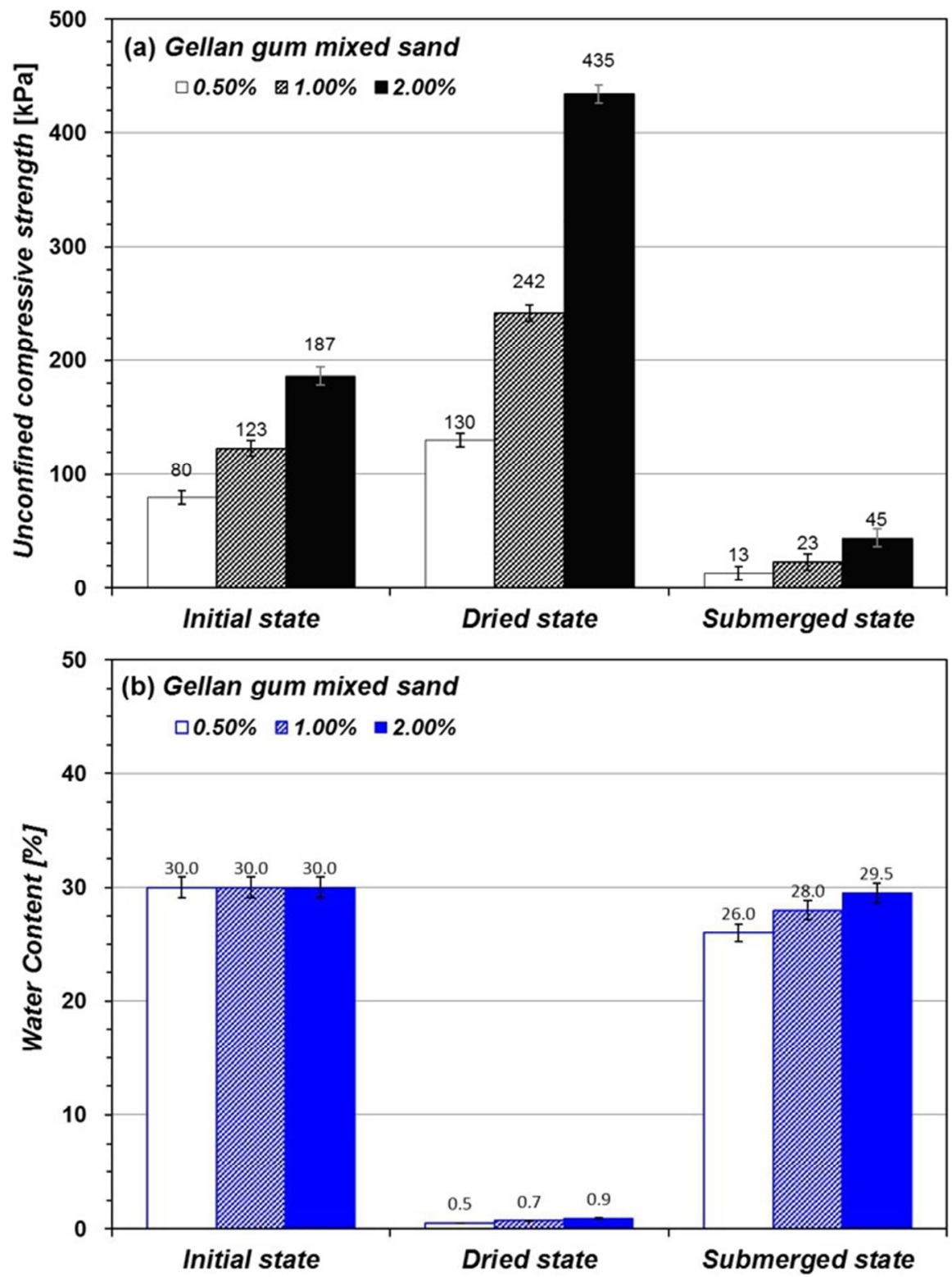

Figure 2. Unconfined compressive strength (a) and water content (b) of gellan gum-treated sand. $126 \times 168 \mathrm{~mm}(150 \times 150 \mathrm{DPI})$ 


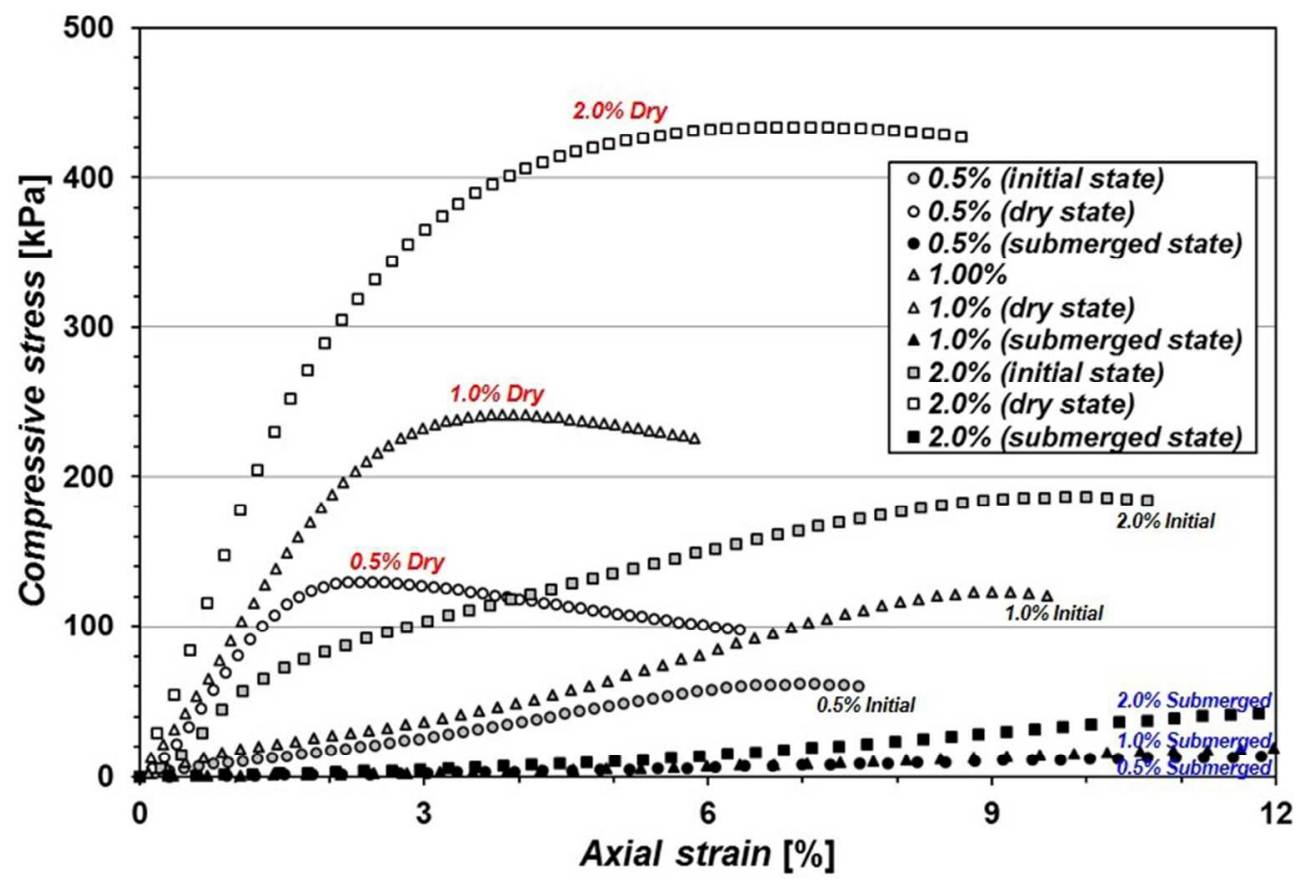

Figure 3. Stress-strain relationships of gellan gum-treated sand under unconfined compression. $144 \times 96 \mathrm{~mm}(150 \times 150 \mathrm{DPI})$ 

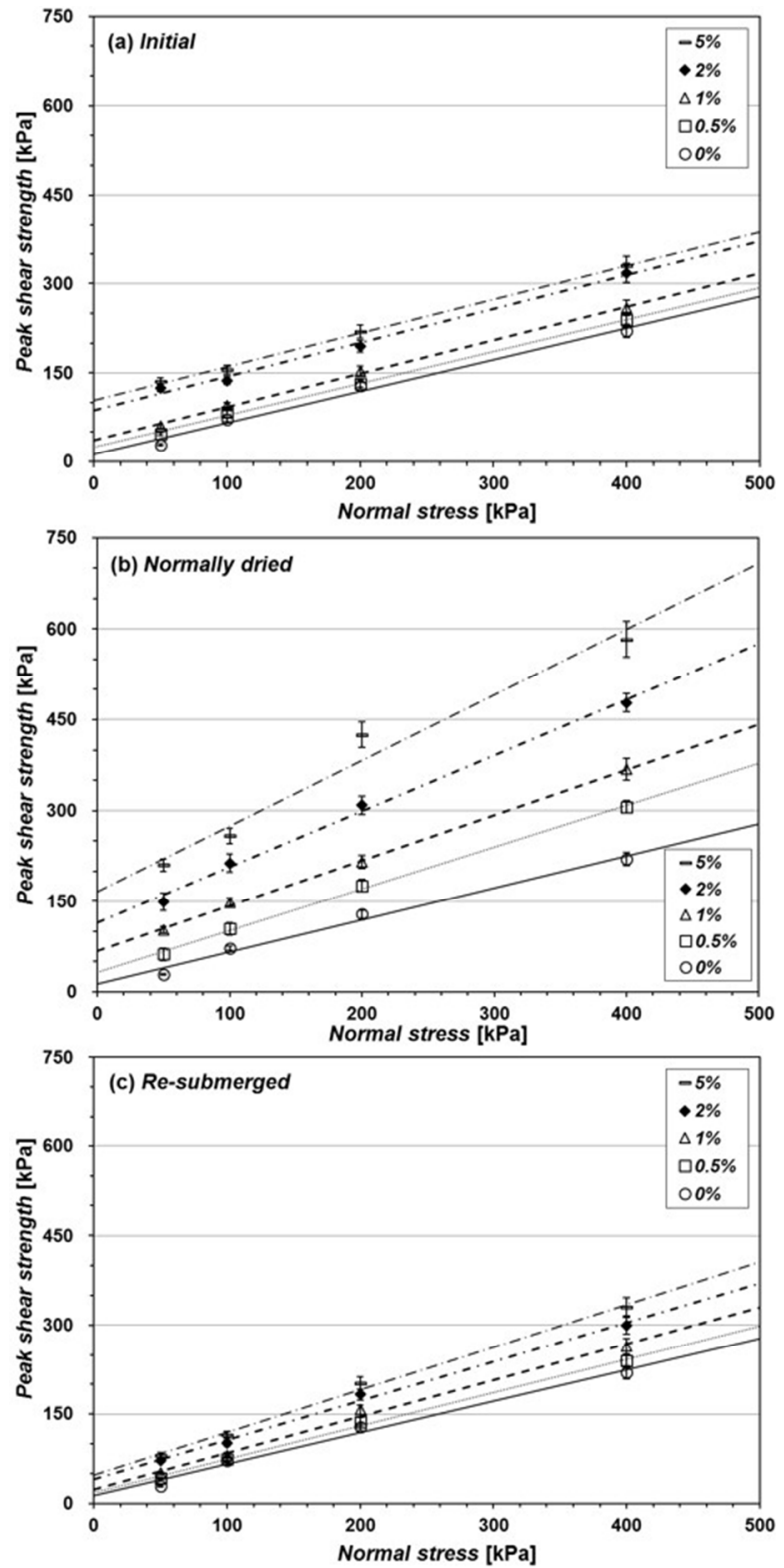

Figure 4. Peak strength of gellan gum-treated sand. (a) Initial condition. (b) Dried condition (28 days). (c) Re-submerged condition ( 24 hours before testing). $85 \times 171 \mathrm{~mm}(150 \times 150 \mathrm{DPI})$ 

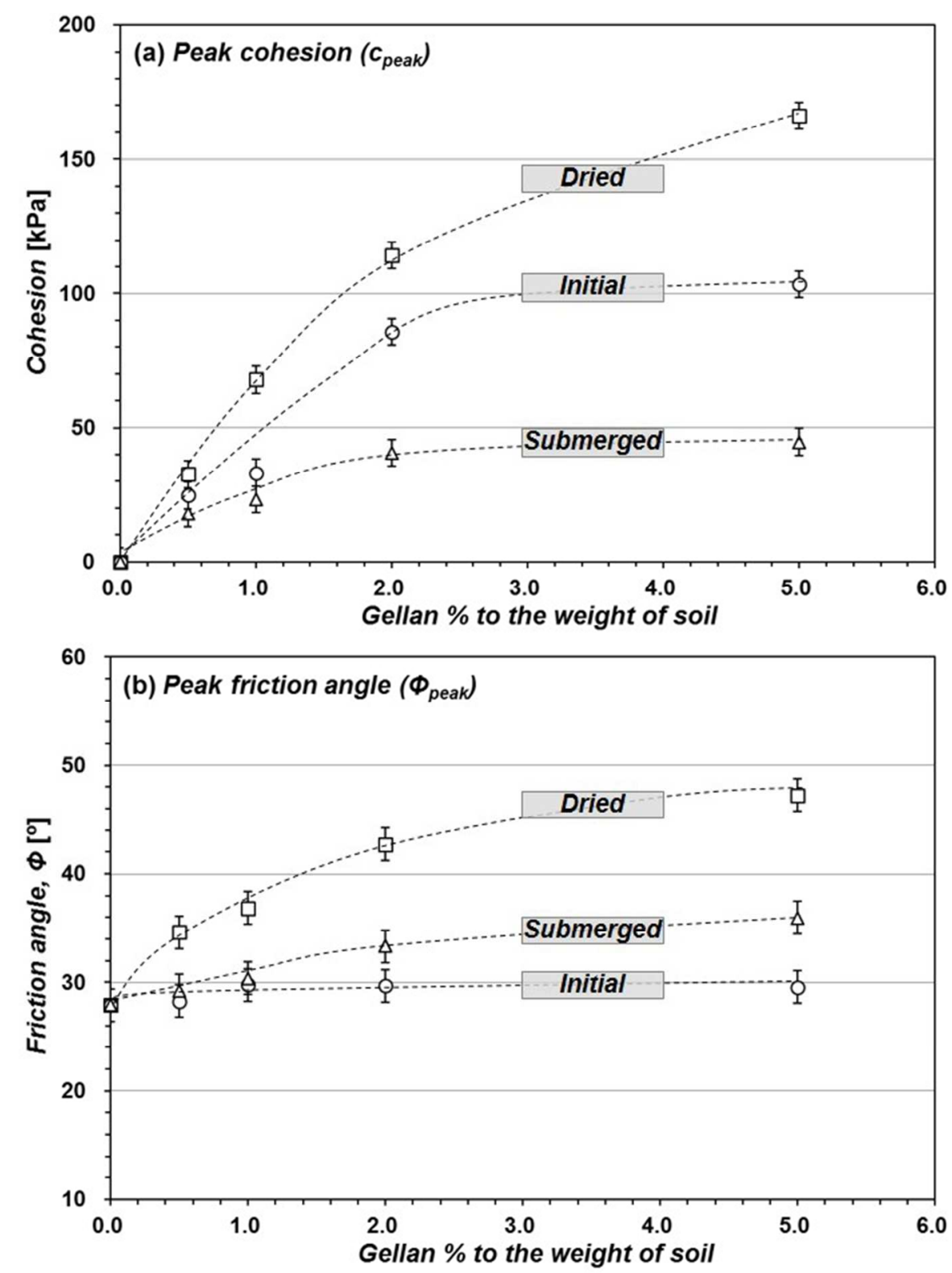

Figure 5. Peak strength properties of gellan gum-treated sand. (a) Cohesion. (b) Friction angle. $120 \times 159 \mathrm{~mm}(150 \times 150 \mathrm{DPI})$ 

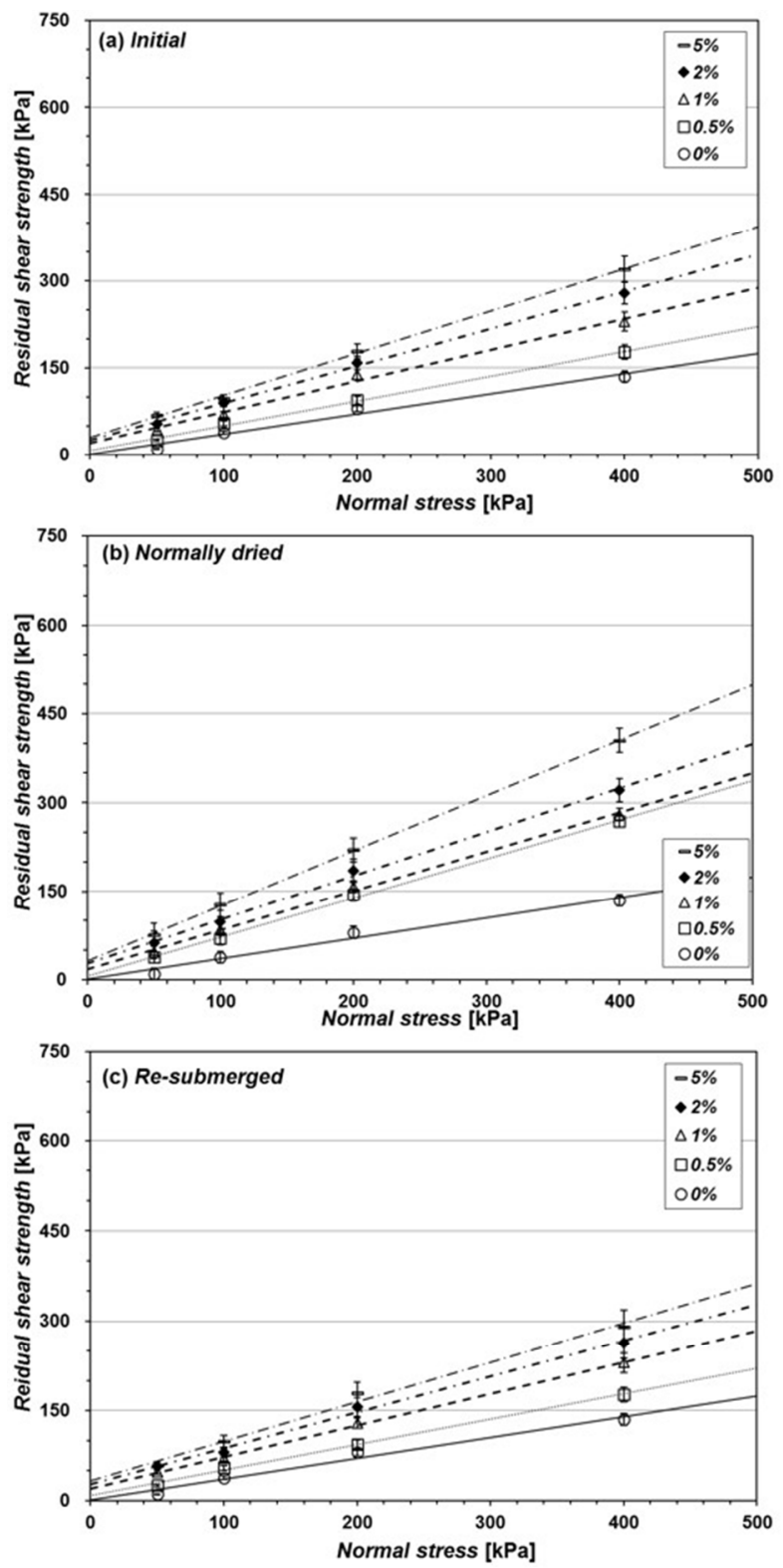

Figure 6. Residual strength of gellan gum-treated sand. (a) Initial condition. (b) Dried condition (28 days). (c) Re-submerged condition (24 hours before testing). $85 \times 171 \mathrm{~mm}(150 \times 150 \mathrm{DPI})$ 

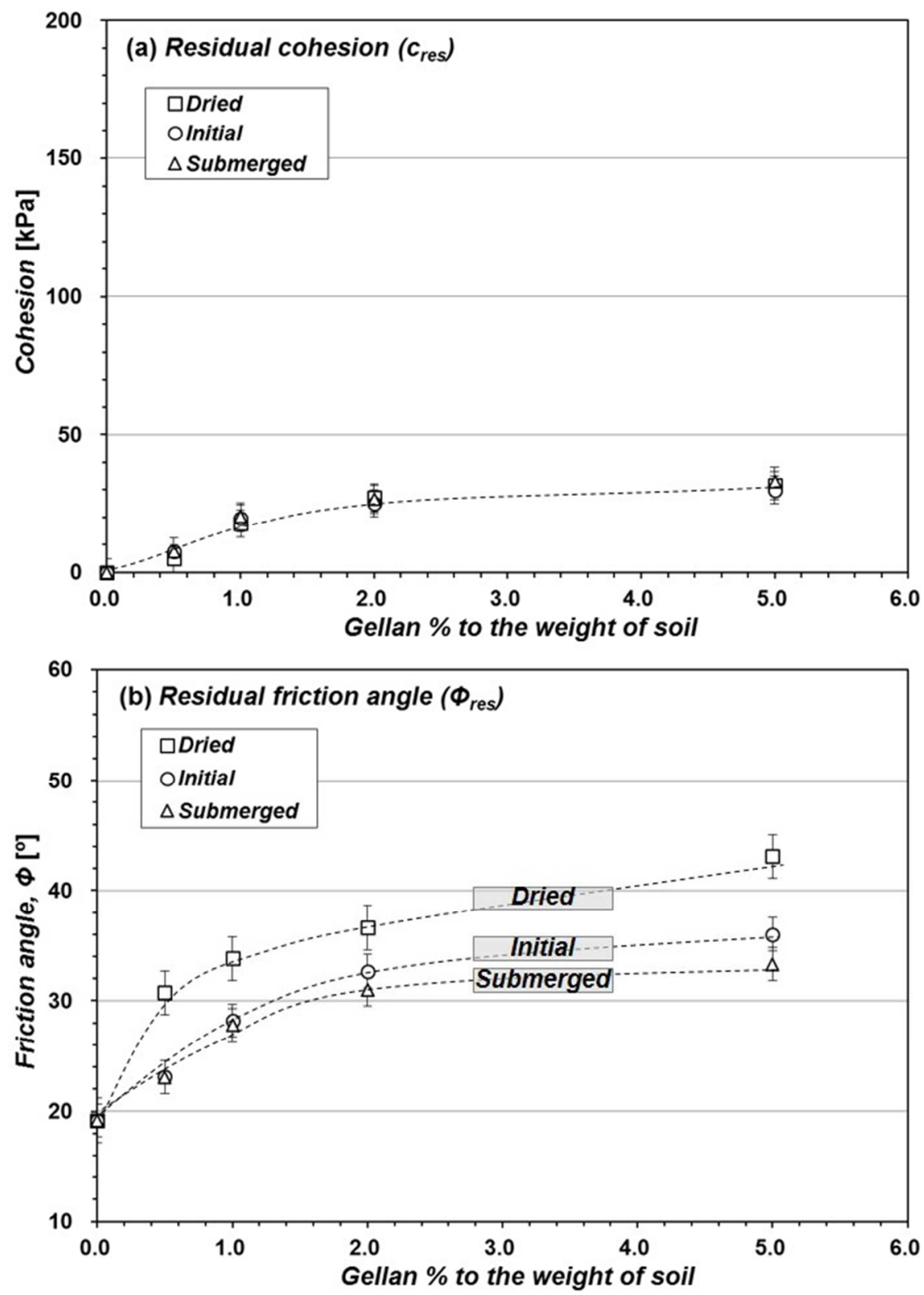

Figure 7. Residual strength properties of gellan gum-treated sand. (a) Cohesion. (b) Friction angle. $120 \times 165 \mathrm{~mm}(150 \times 150 \mathrm{DPI})$ 

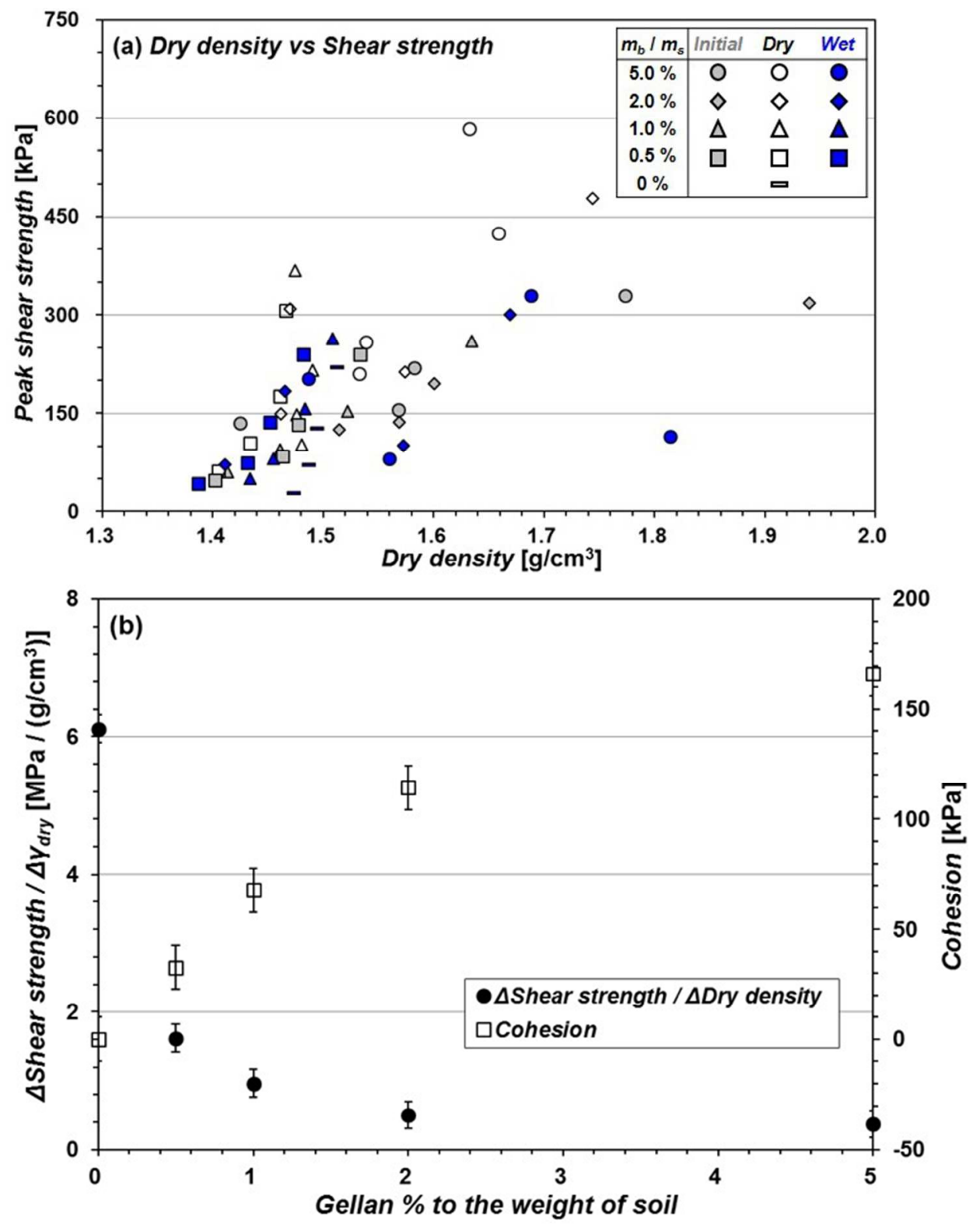

Figure 8. Peak shear strength of gellan gum-treated sand (a) versus dry density (b) versus gellan gum content.

$129 \times 162 \mathrm{~mm}(150 \times 150 \mathrm{DPI})$ 
(a)

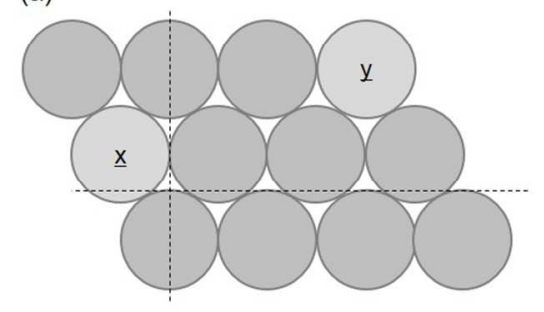

(b)
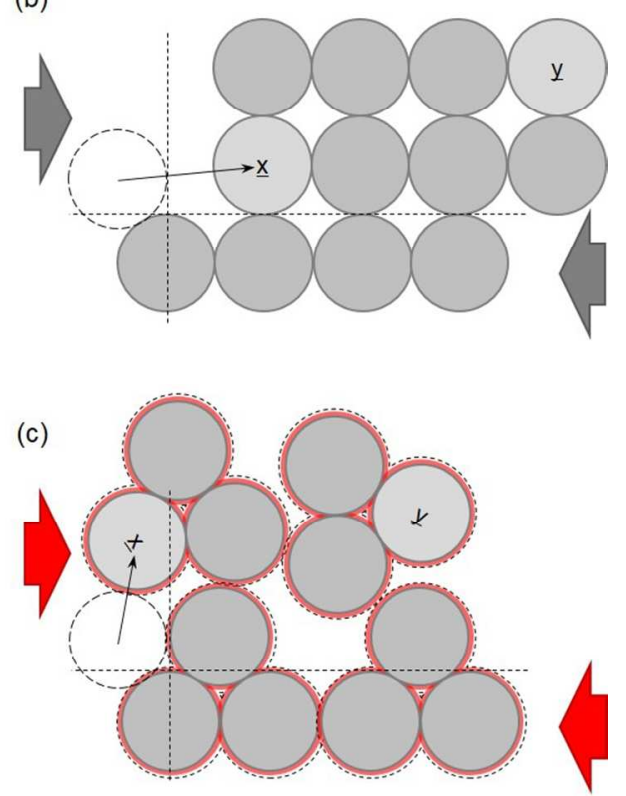

Figure 9. Schematic diagram of sands under shearing. (a) Natural (untreated) sand before shear. (b) Untreated sand under shear in which particles rotate along the shear plane. (c) Aggregation effect of gellan gum-sand mixtures, which induces a higher friction angle ( $\phi$ peak) in a dried condition. $199 \times 126 \mathrm{~mm}(150 \times 150 \mathrm{DPI})$ 


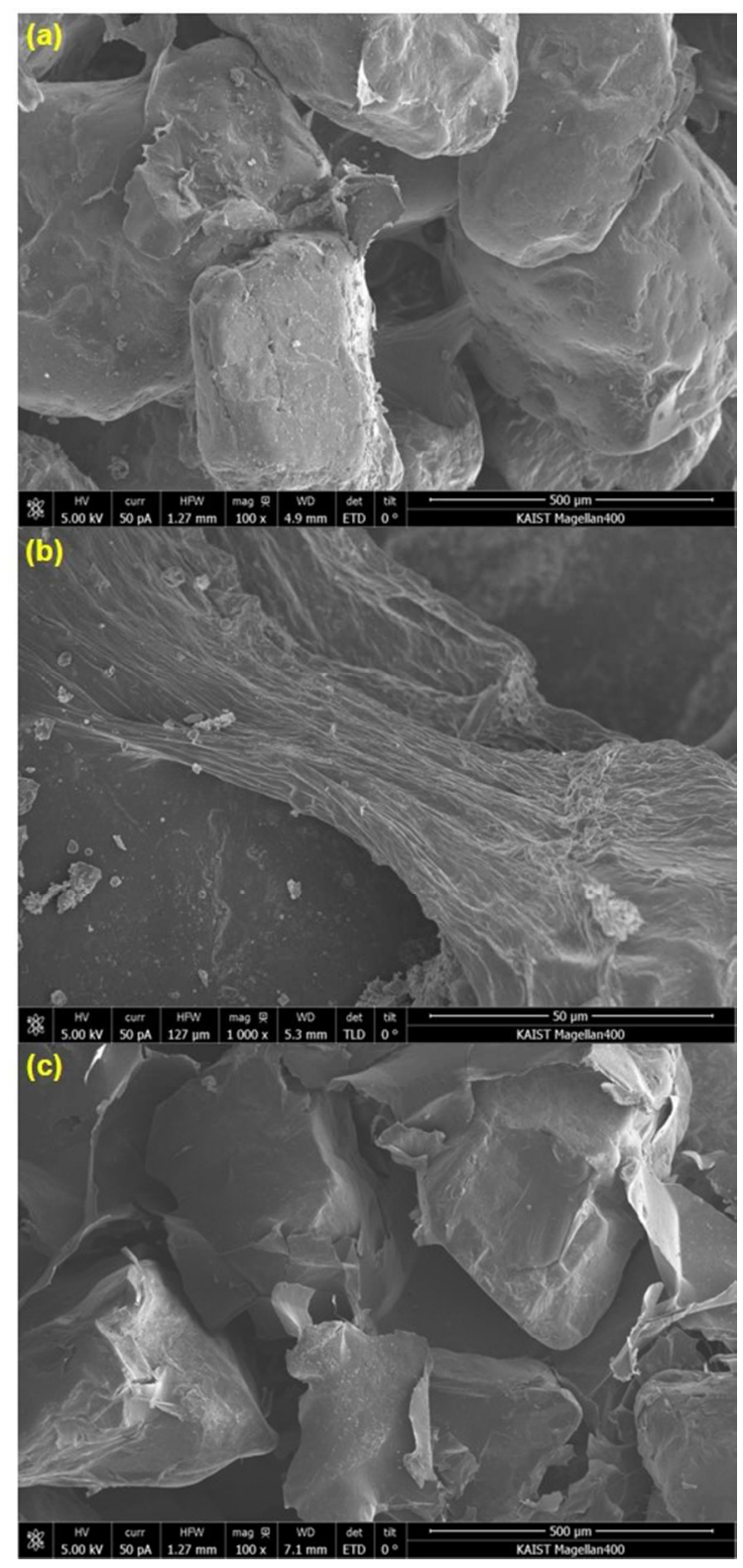

Figure 10. SEM images of $1 \%$ gellan gum-treated sand. (a) Before UTM testing (undisturbed). (b) Gellan gum films accumulated between particles (undisturbed). (c) After UTM testing (crushed) $86 \times 183 \mathrm{~mm}(150 \times 150 \mathrm{DPI})$ 


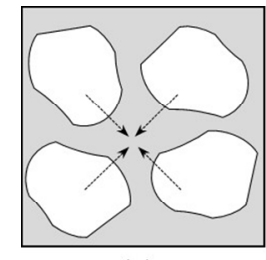

(a)

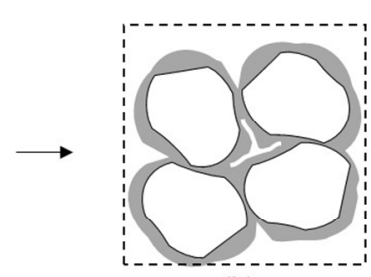

(b)

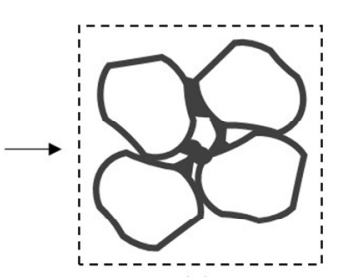

(c)

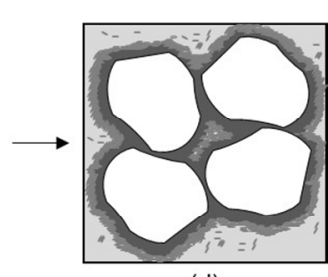

(d)

Figure 11. Drying and wetting mechanisms of gellan treated sands (a) Initial condition. (b) Propagation of cracks in gel with drying. (c) Dried condition. (d) Re-submerged condition. $211 \times 48 \mathrm{~mm}(150 \times 150 \mathrm{DPI})$ 


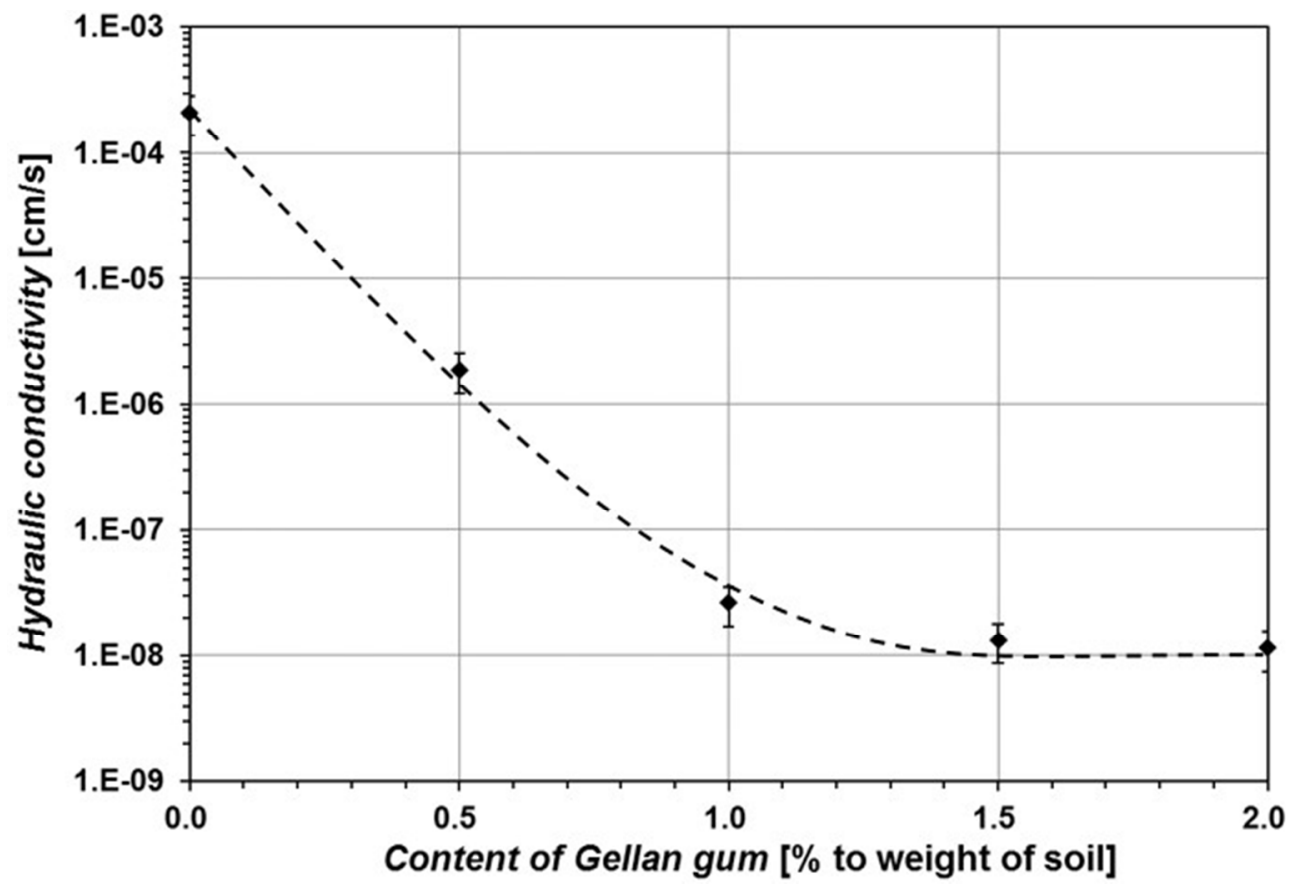

Figure 12. Hydraulic conductivity of gellan gum-treated sand in the initial state (without drying) with biopolymer content (by weight).

$120 \times 80 \mathrm{~mm}(150 \times 150 \mathrm{DPI})$ 